\title{
Modelling, Simulation and Analysis of the Crane Ship Hoisting System
}

\author{
Xiujun $\mathrm{Xu}^{1,} \mathrm{a}$, Zhen $\mathrm{Li}^{1, \mathrm{~b}}$, Liquan Wang ${ }^{1, \mathrm{c}}$, Shaoming $\mathrm{Yao}^{2, \mathrm{~d}}$ and Xiang $\mathrm{Li}^{3, \mathrm{e}}$ \\ ${ }^{1}$ Harbin Engineering University, Harbin, 150001, China; \\ ${ }^{2} \mathrm{AMRC}$ with Boeing, the University of Sheffield, S60 5TZ, UK; \\ ${ }^{3}$ Dalian Neusoft University of Information, Dalian, 116000, China. \\ axuxiujun@hrbeu.edu.cn, blizhen@hrbeu.edu.cn, ‘wangliquan@hrbeu.edu.cn, \\ ds.yao@sheffield.ac.uk, e758470971@qq.com
}

Keywords: Crane ship, Rigid or elastic; Hoisting system, Analytical module, Simulated analysis.

\begin{abstract}
Adams, Simulink, and analytics combined method is created to predict the hoisting operation of crane ships. The flexibility of the boom can be modelled in Adams with a mesh file created by Ansys APDL and 3D visualization can be fulfilled in Adams. With this method, the model of "Offshore Oil 201" is created and the effects of the environment and operation parameters are analyzed. The effect of the environmental interference is considerable, particularly the effect of the wave height. The effect of the pitch rate and rotational speed are both considerable, the pitch rate effects on the swing angle in $X O Z$ plane more than that in $Y O Z$ plane, and the rotational speed effect more on the angle in $Y O Z$ plane. The sling length is also another point to be considered in operation. The results of the sea trail are compared with the simulation results, the error is less than $5 \%$.
\end{abstract}

\section{Introduction}

Plentiful oil and gas reserves have been prospected in the deep ocean, which will be the main resource to be exploited in the future[1,2,3]. Advanced marine engineering equipments are required to make the exploitation efficient and safe. Crane ship has extensively been used to install offshore platforms and unload cargos[4]. Crane ship is a multi-degree of freedom and multi-body system. The motion of hoisting system is affected by the wave load, wind load and other forces[5,6], which make hoisting so hard and even cause the failure of the installation of offshore platforms and the damages of the cargo or ship. It is necessary to build the dynamics model of the crane and hoisting system in the environment of the waves and wind load to ensure an accurate and safe operation of the crane. The hoisting system transient response needs to be analyzed under external interference to reduce the swing of hanging objects as far as possible. The method of multi-rigid body dynamics are adopted by most scholars to study the crane ship with the assumption that the crane ship is rigid and the deformation of the boom and sling is negligible in the dynamic response of hoisting system[7,8].

The coupled motion of the crane and hoisting objects system was investigated, the swinging model of the hoisted object on the crane has been derived by Wang[9]. The swing model of the hoisted object in spheroidal coordinates was established to study the effects of the boom rotation and pitch rate on the motion of the hoisted object by Neupert[10]. The dynamic response of the hoisting system and its control method was studied by Qian[11]. In these studies, the actual calculation of the hoisting process is estimated by an safety factor and the movements and forces cannot be obtain accurately under the given wave load, sea current load, wind load and ship motion[12].

The movement and dynamic response of the ship and hoisting system should be studied in order to create an accurate simulation system and method for the hoisting operation on the sea. At present, the dynamic rigid-flexible coupling model and virtual reality model are hot points to improve the accuracy of the hoisting system simulation[13].

current work is to create a Simulink, Adams and analytical module combined method to predict the motions and loads of the crane ship, hoisting system and hoisted object in various environmental interferences with regard of the flexibility of the boom. Based on the method a virtual 
reality system is created, which can be used for the operation preview under various environmental inferences and object weights.

\section{Offshore Crane Ship and Hoisting Operation}

The target crane ship is Offshore Oil 201, which is the typical crane ship used in current marine engineering.

\subsection{Crane Ship and Operation Environment}

The crane ship can be used to hoist a large object, such as marine buildings, facilities and equipments, from one place to another on the sea, such as offshore platform installation and cargos unloading from an offshore platform or a ship. The crane ship is composed of the crane hull, cabin system, propellers and hoisting system. Hoisting system is composed of the hook, amplitude varying wire rope, boom, A-frame, lifting wire rope, turntable, control cabin, and Bob-weight as shown in Fig. 1(a). The fixed hoisting capacity is 4,000 tons and the rotary hoisting capacity is 3,500 tons.

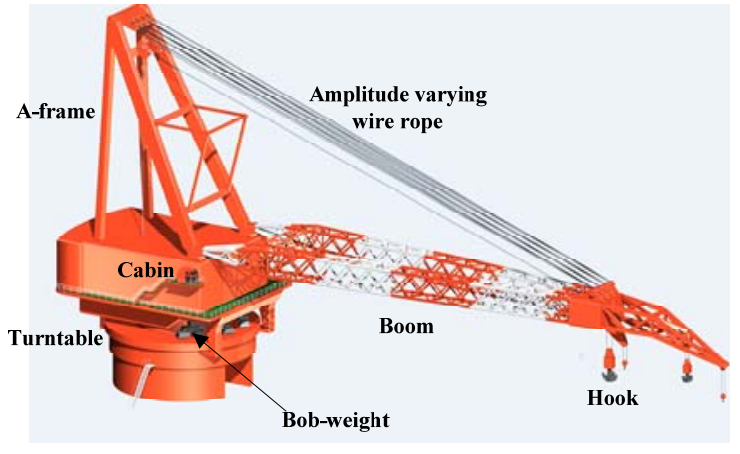

(a) Hoisting system

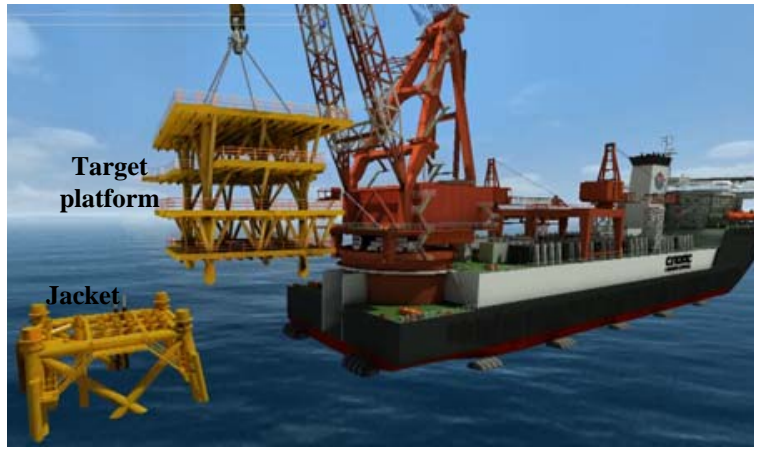

(b) Target installation platform and jacket

Fig. 1 Crane ship system

The most challenging operation of the crane ship is that of the offshore platform installation. The offshore platform is usually up to several thousand tons, which will be hoisted and installed onto the jacket on the sea as shown in Fig. 1(b). The jacket is the space truss that supports the offshore platform. The jacket is pre-fixed on the seabed by steel piles and tension tendons.

\subsection{Control System Schematic}

The crane ship operation is composed of two parts: the ship operation of the ship motion and the hoisting operation. The crane ship control system schematic is shown in Fig. 2.

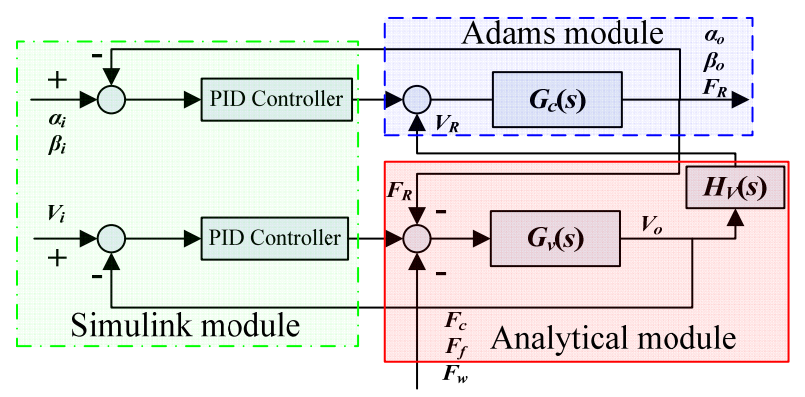

Fig. 2 Control system schematic

Ship movement input, $\mathrm{Vi}$, is the hull displacement input. $\mathrm{Gv}(\mathrm{s})$, is the load transfer function of the hull under seawater damping force and the adjustment of the ballast water tank. Vo is the hull displacement in six degrees of freedom, $[\mathrm{x}, \mathrm{y}, \mathrm{z}, \xi 1, \xi 2, \xi 3]$, including the swaying, surging, heaving, rolling, pitching and yawing. Fc is the sea current load, Ff is the wave load and Fw is the wind load. FR is the general reaction force, including force and torque, produced by the crane. $\alpha o$ is the crane rotation angle output and $\beta o$ is the boom pitch angle output. $\mathrm{Gc}(\mathrm{s})$ is, the hoisting system load transfer function, including the crane, sling and hoisted object. $\alpha \mathrm{i}$ is the crane rotation angle input and $\beta \mathrm{i}$ is the boom pitch angle input. 
The output of the hoisting system includes the swing angle and position of the hoisted object, the sling tension and the general reaction force acting on the hull. Vo is the displacement of the hull in six degrees of freedom.

\section{Modelling}

The crane ship simulation system is composed of Adams module, Simulink module and analytical module and visualization is fulfilled in Adams. The following assumptions are adopted in this simulation: (a) The hull deformation is negligible and the motion of the hull is a forced vibration of a rigid body; (b) The boom of the crane is flexible and will introduce the vibration of an elastic body. The vibration happens in two orthotropic planes ; (c) The sling stiffness is nonlinear, which is positive in tension and zero in compression; (d) The hoisted object (platform) is a cubic.

\subsection{Modelling of the Crane Ship Motion}

The hull located in global coordinate system is shown in Fig. 3.

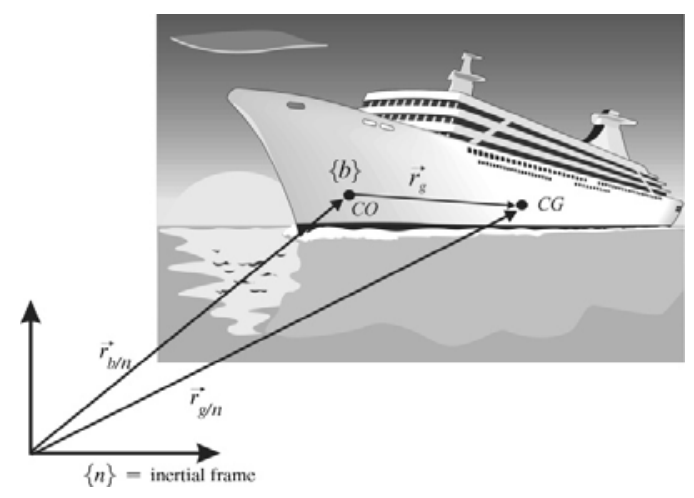

Fig. 3. The model of the ship

As shown in Fig. 3, $\{\mathrm{n}\}$ is the inertial frame of the global coordinate system[14]; $\{\mathrm{b}\}$ is the ship coordinate system with the origin of $\mathrm{CO}(\mathrm{Ob})$; $\mathrm{CG}$ is the hull centre of gravity.

In $\{\mathrm{n}\}$ the following relation is applicable:

$$
\overrightarrow{\boldsymbol{r}}_{g / \mathrm{n}}=\overrightarrow{\boldsymbol{r}}_{b / \mathrm{n}}+\overrightarrow{\boldsymbol{r}}_{g}
$$

Where $\overrightarrow{\boldsymbol{r}}_{g}$ is the displacement vector from the point $\mathrm{CO}$ to the point $\mathrm{CG}, \vec{r}_{b / n}, \vec{r}_{g / n}$ are the position vectors of the point $\mathrm{CO}$ and point $\mathrm{CG}$ in $\{\mathrm{n}\}$.

In $\{b\}$ the position of the hull gravity centre is:

$$
r_{g}^{b}=\left[x_{G}, y_{G}, z_{G}\right]^{T}=\vec{r}_{g / \mathrm{n}}-\vec{r}_{b / \mathrm{n}} .
$$

Force equation is[15]:

$$
\boldsymbol{M}_{R B} \dot{v}+\boldsymbol{C}_{R B}(v) v=\tau_{R B},
$$

Where MRB is the mass matrix; $\mathrm{v}=[\mathrm{u}, \kappa, \mathrm{w}, \mathrm{p}, \mathrm{q}, \mathrm{r}] \mathrm{T}$ is the general velocity and general angular velocity; $\tau R B=[X, Y, Z, K, M, N]$ is the general force and general moment; $\mathrm{CRB}$ is the Coriolis centripetal force matrix.

Hydrodynamics is also necessary to be involved in the hull modelling $[16,17]$. When the hydrodynamic added mass and hydrodynamic damping are involved in, the model of the ship can be rewritten as:

$$
\boldsymbol{M}_{R B} \dot{\boldsymbol{v}}+\boldsymbol{C}_{R B}(v) v+\boldsymbol{M}_{A} \dot{v}_{r}+\boldsymbol{C}_{A}\left(v_{r}\right) v_{r}+\boldsymbol{D}\left(v_{r}\right) v_{r}=\boldsymbol{\tau}_{\text {wind }}+\boldsymbol{\tau}_{\text {wave }}+\boldsymbol{\tau}_{\text {current }}+\boldsymbol{\tau}_{\text {control }},
$$

Where, MAvr+CA(vr)vr is the hydrodynamic force, MA is the hydrodynamic added mass matrix, $\mathrm{CA}$ is the Coriolis centripetal force matrix caused by the hydrodynamic added mass, $\mathrm{D}(\mathrm{vr}) \mathrm{vr}$ is the hydrodynamic damping force, $\mathrm{D}(\mathrm{vr})$ is the hydrodynamic damping matrix, $\mathrm{vr}$ is the relative velocity between hull and sea water. $\tau$ wind is the wind load, $\tau$ wave is the wave load, $\tau$ curent is the current load, $\tau$ control is the general control force.

Mass matrix of the ship, including the hydrodynamic added mass, is: 


$$
\boldsymbol{M}_{R B}=\left[\begin{array}{cccccc}
M & 0 & 0 & 0 & M . Z_{G C} & -M . Y_{G C} \\
0 & M & 0 & -M . Z_{G C} & 0 & -M . X_{G C} \\
0 & 0 & M & M . Y_{G C} & -M . X_{G C} & 0 \\
0 & -M . Z_{G C} & M . Y_{G C} & I_{44} & I_{45} & I_{46} \\
M . Z_{G C} & 0 & -M . X_{G C} & I_{54} & I_{55} & I_{56} \\
-M . Y_{G C} & M . X_{G C} & 0 & I_{64} & I_{65} & I_{66}
\end{array}\right] \text {, }
$$

Where $M$ is the sum of the ship mass and added mass, $\operatorname{Iij}(\mathrm{i}=\mathrm{j})$ are the inertia moments around the Obx axis, Oby axis and Obz axis, $\mathrm{Iij}(\mathrm{i} \neq \mathrm{j})$ are the inertia products on the Obxy plane, Obyz plane and Obzx plane.

The coordinates, $\mathrm{XGC}, \mathrm{YGC}$ and $\mathrm{ZGC}$ in $\{\mathrm{b}\}$ are:

$$
\begin{aligned}
& X_{G C}=X_{G}-X_{c a l} \\
& Y_{G C}=Y_{G}-Y_{c a l}, \\
& Z_{G C}=Z_{G}-Z_{c a l}
\end{aligned}
$$

Where $X G, Y G$ and ZG are the position coordinates of the hull gravity centrein $\{b\}, X c a l, Y c a l$ and Zcal are the position coordinates of the calculated points in coordinate system $\{b\}$.

The mass matrix MRB can be expressed in the following form:

$$
\boldsymbol{M}_{R B}=\boldsymbol{M}_{R B}^{T}=\left[\begin{array}{ll}
\boldsymbol{M}_{11} & \boldsymbol{M}_{12} \\
\boldsymbol{M}_{22} & \boldsymbol{M}_{22}
\end{array}\right]>0 .
$$

Thus the Coriolis centripetal force matrix is:

$$
C_{R B}(v)=\left[\begin{array}{cc}
0_{3 \times 3} & -M_{11} v_{1}+\mathrm{M}_{12} v_{2} \\
-M_{11} v_{1}+\mathrm{M}_{12} v_{2} & -M_{21} v_{1}+\mathrm{M}_{22} v_{2}
\end{array}\right],
$$

where $\mathrm{v} 1=[\mathrm{u}, \kappa, \mathrm{w}] \mathrm{T}$ is the line velocity vector, $\mathrm{v} 2=[\mathrm{p}, \mathrm{q}, \mathrm{r}] \mathrm{T}$ is the angular velocity vector.

\subsection{Modelling of Environmental Interference}

\subsubsection{Wave Force Modelling}

Based on the two-parameter spectrum recommended by International Towing Tank Conference and International Ship Structure Congress [18], the wave force can be defined as:

$$
S(\omega)=\frac{173 H_{1 / 3}^{2}}{T_{1}^{4} \omega^{5}} \exp \left(-\frac{691}{T_{1}^{4} \omega^{4}}\right),
$$

Where $\mathrm{H} 1 / 3$ is one third of the righteous wave, $\omega$ is the angular frequency, T1 is the spectral central period, which is around the visual mean period and can also be expressed by the peak period, $\mathrm{T} 0$, in the wave spectrum, and the relation is $\mathrm{T} 0=1.2965 \mathrm{~T} 1$.

The mathematical expression of the random irregular wavefront elevation function with regard of the random initial phase can be written as[19]:

$$
\zeta(x, y, t)=\sum_{i=1}^{n} \sum_{j=1}^{m} A_{i, j} \cos \left(k_{i} x \cos \theta_{j}+k_{i} y \sin \theta_{j}-\omega_{i} t+\varphi\right),
$$

Where $\mathrm{A}$ is the amplitude; $\mathrm{k}$ is the wave number; $\varphi$ is the initial phase angle; $\theta$ is the wave direction angle; $t$ is the time; $x$ and $y$ are the wave position coordinates in the inertial frame.

Ship motion or load in wave can be calculated from the wave spectrum and response amplitude operator(RAO Curve). RAO is a concept of engineering statistics, which is the transfer function from the wave excitation to the hull movement[20]. The RAO curve is obtained in the towing tank experiment.

In current work, the wave load can be expressed as:

$$
\tau_{\text {wave }}=F_{\text {wave }}=H(\omega, \theta, U) \zeta(x, y, t),
$$

Where $\mathrm{H}(\omega, \theta, \mathrm{U})$ is RAO Curve, $\omega$ is the wave angular frequency, $\theta$ is the direction angle, $\mathrm{U}$ is the relative velocity between the wave and the hull and $\zeta(\mathrm{x}, \mathrm{y}, \mathrm{t})$ is the wavefront elevation function.

\subsubsection{Wind Load Modelling}

The wind load can be calculated according to the empirical formula or wind tunnel experiment. The wind tunnel experiment is more specific and accurate. In current work the wind load is calculated according to the wind tunnel experimental results[21]. The expressions of the force and moment acting on the hull can be expressed as: 


$$
\tau_{\text {wind }}=\left\{\begin{array}{l}
X_{W}=0.5 \rho_{a} A_{f} U_{R}^{2} C_{w x}\left(\alpha_{R}\right) \\
Y_{W}=0.5 \rho_{a} A_{s} U_{R}^{2} C_{w y}\left(\alpha_{R}\right) \\
N_{W}=0.5 \rho_{a} A_{s} L_{O A} U_{R}^{2} C_{w n}\left(\alpha_{R}\right)
\end{array},\right.
$$

Where, air density, $\rho$ a, is $1.204 \mathrm{~kg} / \mathrm{m} 3$, UR is the relative wind speed, LOA is the hull length, Af and As are the front projection area and side projection area of the hull above the water, $\operatorname{Cwx}(\alpha \mathrm{R})$, $\mathrm{Cwy}(\alpha \mathrm{R})$ and $\mathrm{Cwn}(\alpha \mathrm{R})$ are the wind pressure coefficients obtained in wind tunnel experiments and the relative hull height is HLM=As/LOA.

\subsubsection{Current Load Modeling}

The ocean current produced force and moment acting on the hull can be expressed as[22]:

$$
\tau_{\text {current }}=\left\{\begin{array}{l}
X_{c}=0.5 \rho U_{c}^{2} A_{c}^{f} C_{c x}(\beta) \\
Y_{c}=0.5 \rho U_{c}^{2} A_{c}^{s} C_{c y}(\beta) \\
N_{c}=0.5 \rho U_{c}^{2} A_{c}^{s} L_{O A} C_{c n}(\beta)
\end{array},\right.
$$

Where, $\rho$ is the density of sea-water, $U_{C}$ is relative current rate, $A_{c}{ }^{f}$ and $A_{c}{ }^{s}$ are the front projection area and side projection area of ship hull underwater, $\operatorname{Ccx}(\beta), \operatorname{Ccy}(\beta)$ and $\operatorname{Ccn}(\beta)$ are current moment coefficients obtained in towing tank experiments, $\beta$ is the ocean current angle in ship coordinate system, which is 0 if the current is along the $X$ direction and clockwise is positive, the range is $\left[0^{\circ}, 360^{\circ}\right)$.

\subsection{Adams Module and Visualization}

The ship geometry should be simplified in advance to improve the simulation efficiency without considerable errors introduced. The hull, crane turntable and boom have been simplified and keep the overall dimensions unchanged, as well as the original mass, effective moment of inertia and other effective parameters. The prototype geometric model is created in Solidworks, as shown in Fig. 4(a).

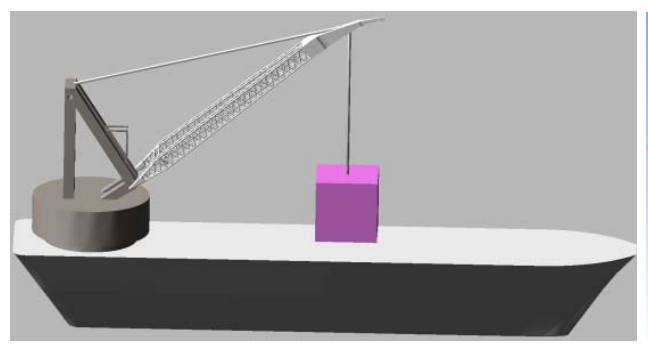

(a) Geometric model of the crane ship

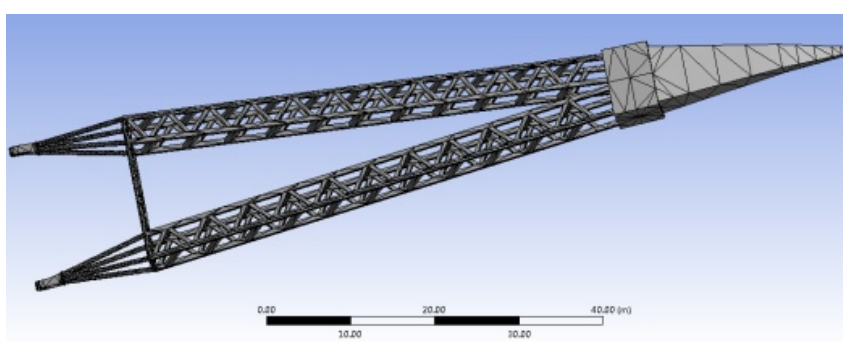

(b) Mesh of the boom

Fig. 4 Modelling and flexible of crane ship

The hoisting system is composed of the flexible boom and sling. The boom is meshed in Ansys APDL and import the MNF file into Adams. The mesh of the boom is shown in Fig. 4(b).

The stiffness of the wire rope is nonlinear when the boom vibrates. It will not only increase the computational load, but also make the simulation does not converge well. It is necessary to linearize the sling stiffness in the current work. The nonlinear stiffness of the wire rope is shown in Fig. 5 and the wire rope can be treated as approximately quasi-linearized according to the nonlinear vibration theory.

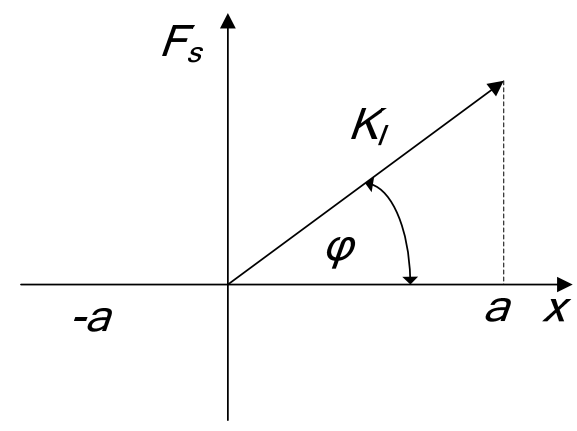

Fig. 5 Spring stiffness linearization of the wire rope 
Suppose the displacement is:

$$
x_{1}=a \cos \varphi
$$

Elastic restoring coefficient, $F_{s}$, is:

$$
F_{s}(a \cos \varphi)=\left\{\begin{array}{ccc}
0 & -a \leq x<0 & (-\pi \leq \varphi<0) \\
K_{l} a \cos \varphi & 0 \leq x<a & (0<\varphi<\pi)
\end{array} .\right.
$$

Equivalent linear restoring force is:

$$
P(a)=\frac{1}{\pi} \int_{0}^{2 \pi} F_{s}(a \cos \varphi) \cos \varphi d \varphi=\frac{K_{l}}{2} \bullet a,
$$

Where $K_{l}$ is the slope of the elastic restoring coefficient.

The linear equivalent stiffness of the wire ropes can be expressed as:

$$
K_{R}=\frac{1}{2} \cdot \frac{5}{2} \cdot \frac{E A}{l_{0}}=\frac{1.25 E A}{l_{0}},
$$

Where, $E$ and $A$ are the elastic modulus and cross sectional area of the wire rope.

The wire rope can be idealized as the spring border of the boom with a stiffness of $K_{R}$.

Adams virtual prototype is shown in Fig. 6(a). The six DOFs, $x, y, z, \xi_{1}, \xi_{2}$ and $\xi_{3}$, of the crane ship are swaying, surging, heaving, rolling, pitching and yawing.

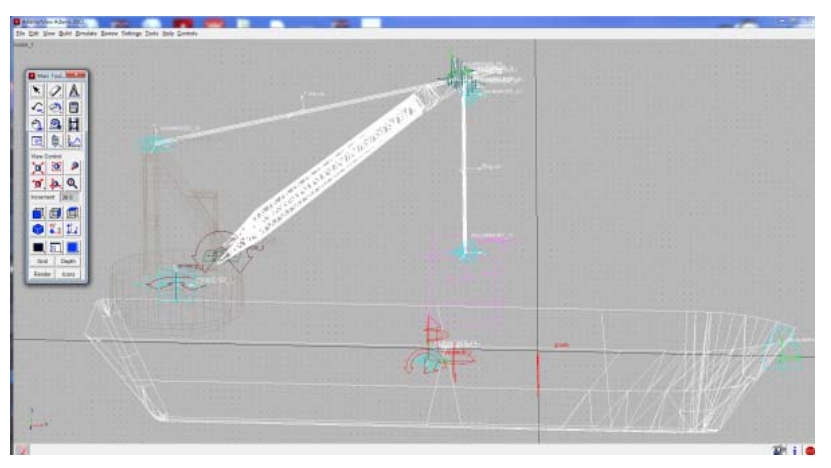

(a) Virtual prototype in Adams

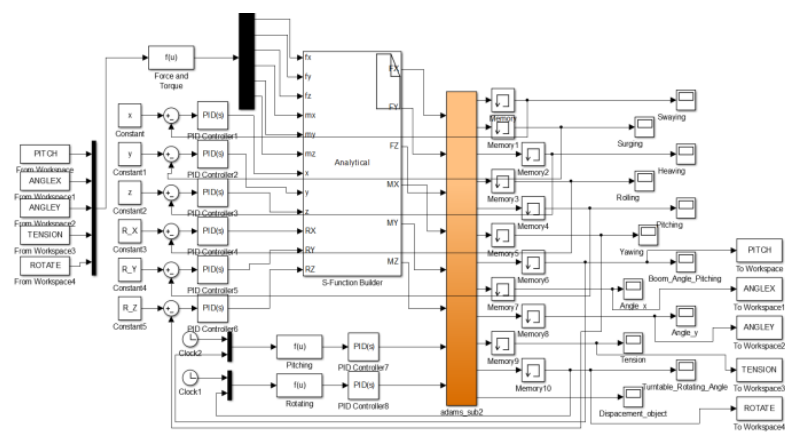

(b) Simulink module

Fig. 6 Virtual prototype model of crane ship

In the current work the analytical module will cooperate with Matlab and Adams modules to simulate the dynamic response of the crane ship. Within the Adams module the variables, which can be obtained, are: sling tension, location and angle of the hoisted object, and the reaction force and torque produced by the hoisting system acting on the hull.

The control model is created in Simulink including eight PID controllers as shown in Fig. 6(b) as well as feedbacks from Adams module and analytical module and the output will communicate with Adams module and analytical module. The Analytical module has twelve inputs and six outputs in total. The twelve inputs include six reaction forces and moments produced by the hoisting system, and the six hull control forces and torques, which compose $\boldsymbol{\tau}_{\text {control }}$ in the analytical model. The six outputs are the displacements of the ship in the six degrees of freedom. Six controllers are designed to control the ship control force in six degrees of freedom and the other two are used to control the turntable and the pitch movement of the boom.

\section{Simulation and Analysis}

Based on the above simulation system case studies will be carried out and analyzed in this section.

\subsection{Effects of the Environmental Interference}

In the ocean environment, wave and current is associated with each other. In this article the current and wave are supposed to be independent to understand their effects on the hull movement. Three environment settings are investigated. The setting 1 with a wave height of $2 \mathrm{~m}$ and a current velocity of $0.31 \mathrm{~m} / \mathrm{s}$ is listed in Table 1 . The setting 2 with a wave height of $4 \mathrm{~m}$ and the current velocity of $0.31 \mathrm{~m} / \mathrm{s}$. The setting 3 with a wave height of $2 \mathrm{~m}$ and the current velocity of $0.62 \mathrm{~m} / \mathrm{s}$ listed. The supposed weight of the hoisted platform is 2400 tons. 
Table 1. Environment Settings

\begin{tabular}{cccccc}
\hline Parameters & Wind Velocity & Current Velocity & Wave Height & Wave Direction & Peak period \\
\hline Setting 1 & $10 \mathrm{~m} / \mathrm{s}$ & $0.31 \mathrm{~m} / \mathrm{s}$ & $2 \mathrm{~m}$ & $90^{\circ}$ & $10 \mathrm{~s}$ \\
Setting 1 & $10 \mathrm{~m} / \mathrm{s}$ & $0.31 \mathrm{~m} / \mathrm{s}$ & $2 \mathrm{~m}$ & $90^{\circ}$ & $10 \mathrm{~s}$ \\
Setting 1 & $10 \mathrm{~m} / \mathrm{s}$ & $0.31 \mathrm{~m} / \mathrm{s}$ & $2 \mathrm{~m}$ & $90^{\circ}$ & $10 \mathrm{~s}$ \\
\hline
\end{tabular}

The instruction sequence is shown in Fig.7. The red line represents the hook height from the sea level, the blue dotted line is the rotation angle of the turntable. The total simulation time of the hoisting operation is the 660 seconds. The platform is hoisted at from $250^{\text {th }}$ seconds and put down from $650^{\text {th }}$ seconds. The hoisted object has ten seconds loading time (hook on) before hoisted and unloading time (hook off) after put down. The way of the hoisting is tail-suspension.

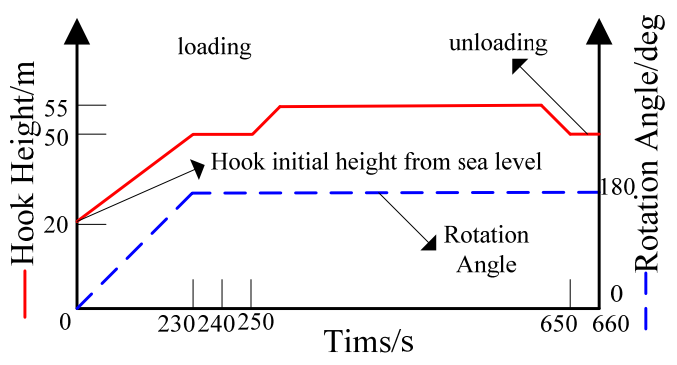

\subsubsection{Effects on the Ship Movement}

Fig. 7 The instruction sequence diagram

The origin, $\mathrm{O}$, of the hoisting coordinate system is located at the endpoint of the boom. The $Z$ axis points upward. The $X$ axis is defined within the plane composed by $Z$ axis and the line from the boom root to the boom top and pointing to the boom top. The $Y$ axis is perpendicular to the plane composed by $X$ axis and $Z$ axis with its direction according to the right-hand rule. The swing angle, $P h i$, is the angle between the sling and its projection in the $X O Z$ plane. The swing angle, Theta, is the angle between the projection of the sling in the $X O Z$ plane and the $Z$ axis.

The time responses of the ship's displacements under three environment settings are shown in Fig. 8, Fig. 9 and Fig. 10.

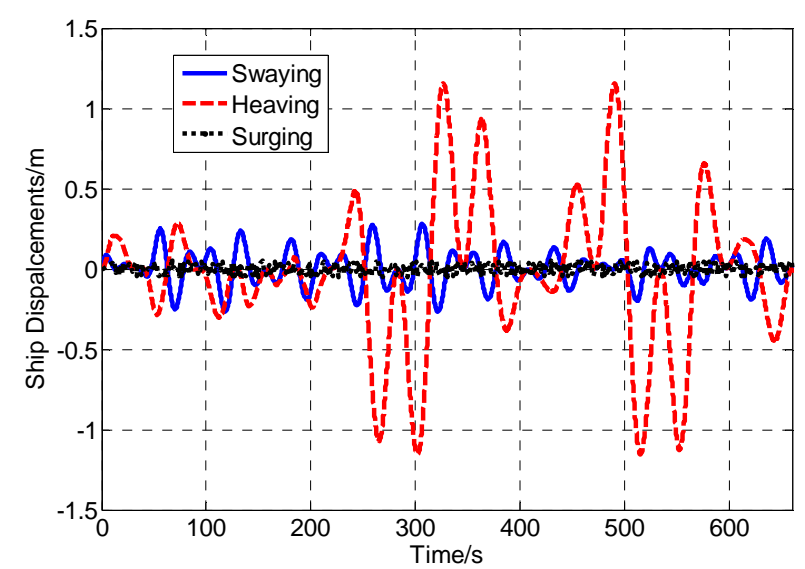

(a) Ship displacement curve

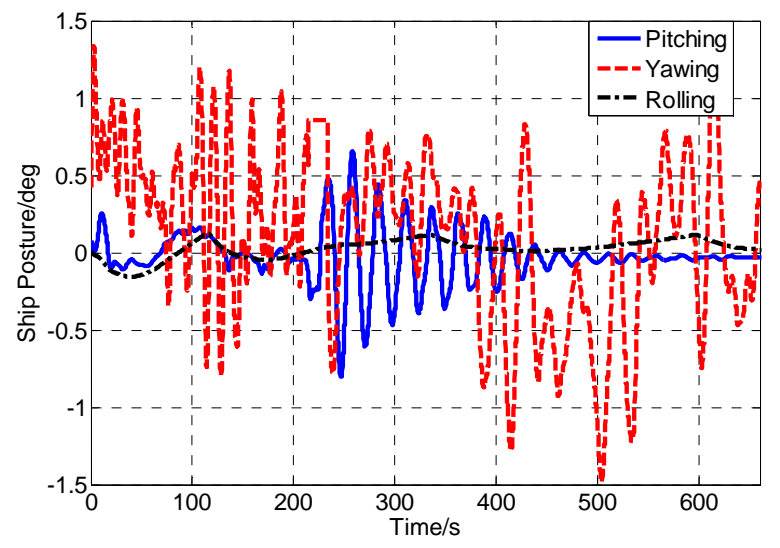

(b) Ship posture curve

Fig. 8 Ship six degrees of freedom under setting 1 


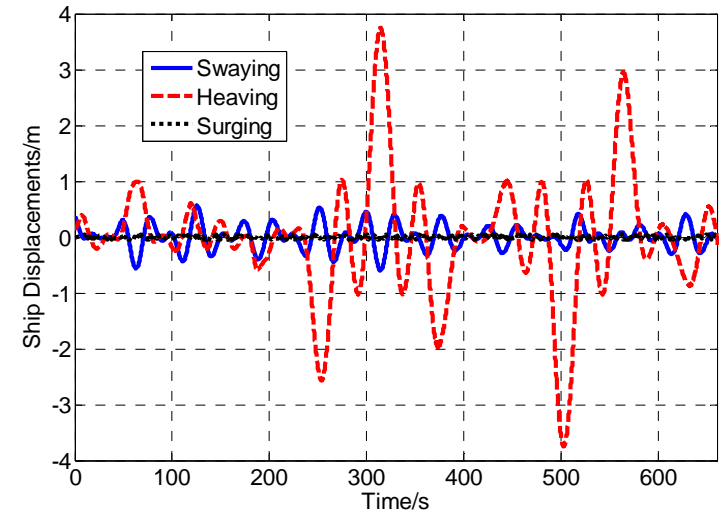

(a) Ship displacement curve

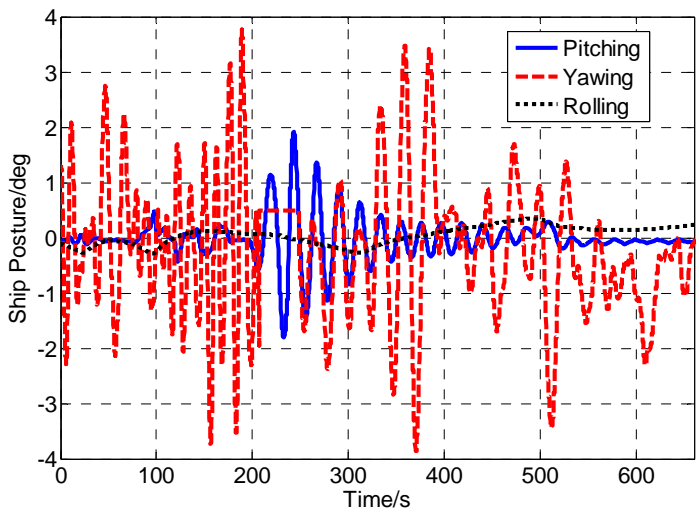

(b) Ship posture curve

Fig. 9 Ship six degrees of freedom under setting 2

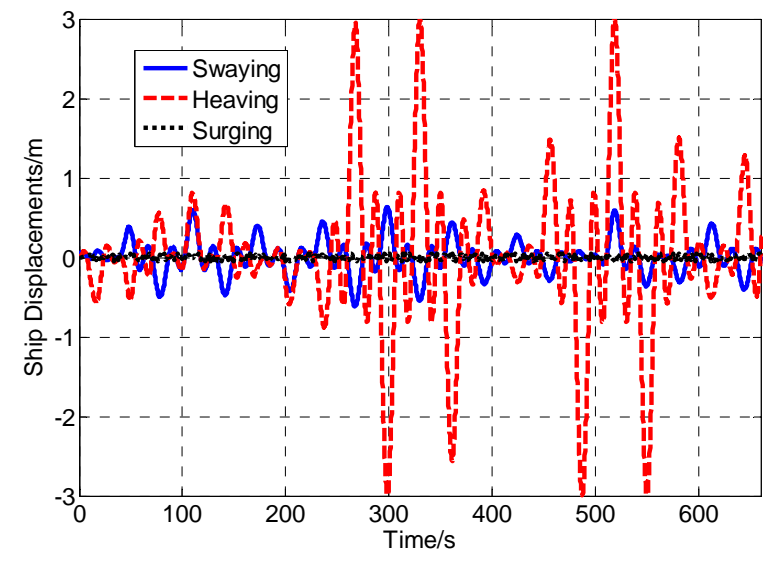

(a) Ship displacement curve

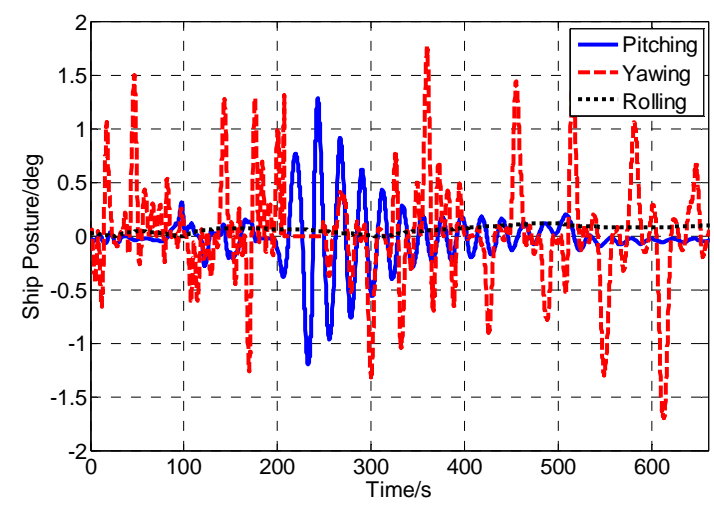

(b) Ship posture curve

Fig. 10 Ship six degrees of freedom under setting3

As shown in Fig. 8(a) and Fig. 9(a) the heaving amplitude of the crane ship increases significantly from the $250^{\text {th }}$ second when the platform is hoisted. This is because the reaction force from hoisting system on the hull. The maximum amplitude of the ship heaving is about 1.2 meters under environment setting 1 with a wave height of $2 \mathrm{~m}$, and it increases to 3.8 meters under environment setting 2 with a wave height of $4 \mathrm{~m}$, which is 3.17 times of the setting 1 . The ship swaying increases by $0.25 \mathrm{~m}$ and the surging remains unchanged when the wave height is doubled and the influence of the hoisted object mass on the ship swaying is not considerable. The ship yawing amplitude increases from $1.4^{\circ}$ to $3.8^{\circ}$, the pitching amplitude increases from $0.7^{\circ}$ to $2^{\circ}$, and the rolling amplitude from $0.2^{\circ}$ to $0.3^{\circ}$ when the waves height changes from $2 \mathrm{~m}$ to $4 \mathrm{~m}$.

The current velocity effects can be seen to compare Fig. 8 with Fig. 9. The maximum amplitude of the ship heaving increases from $1.2 \mathrm{~m}$ sunder environment setting 1 to $3.0 \mathrm{~m}$ under environment setting 2, which is 2.5 times of the setting 1. The ship swaying increases from 0.3 meters to 0.5 meters and the surging remains unchanged when the current velocity increases from $0.31 \mathrm{~m} / \mathrm{s}$ to $0.62 \mathrm{~m} / \mathrm{s}$, the influence of the hoisted object mass on the ship swaying is not considerable. The ship yawing amplitude increases from $1.4^{\circ}$ to $1.8^{\circ}$, the pitching amplitude increases from $0.7^{\circ}$ to $1.25^{\circ}$, and the rolling amplitude has not be changed approximately when the current velocity changes from $0.31 \mathrm{~m} / \mathrm{s}$ to $0.62 \mathrm{~m} / \mathrm{s}$.

\subsubsection{Effects on the Hoisting System}

In this simulation, the swing angles and sling tensions under various environment settings are analyzed. The time response of the swing angles and tension of the sling are shown in Fig. 11. 


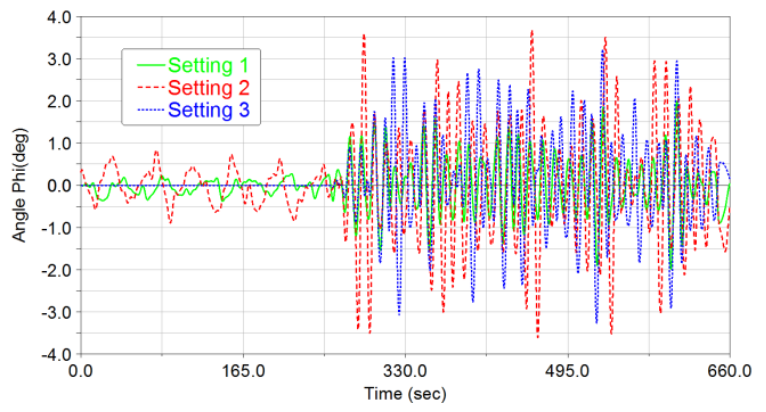

(a) Time response of the angle Phi

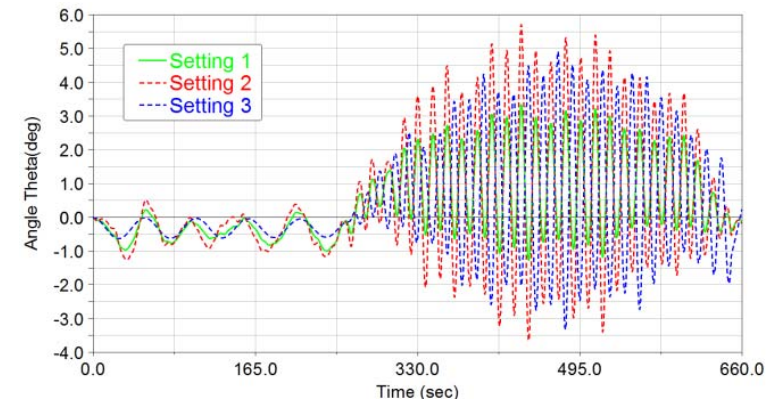

(b) Time response of the angle Theta

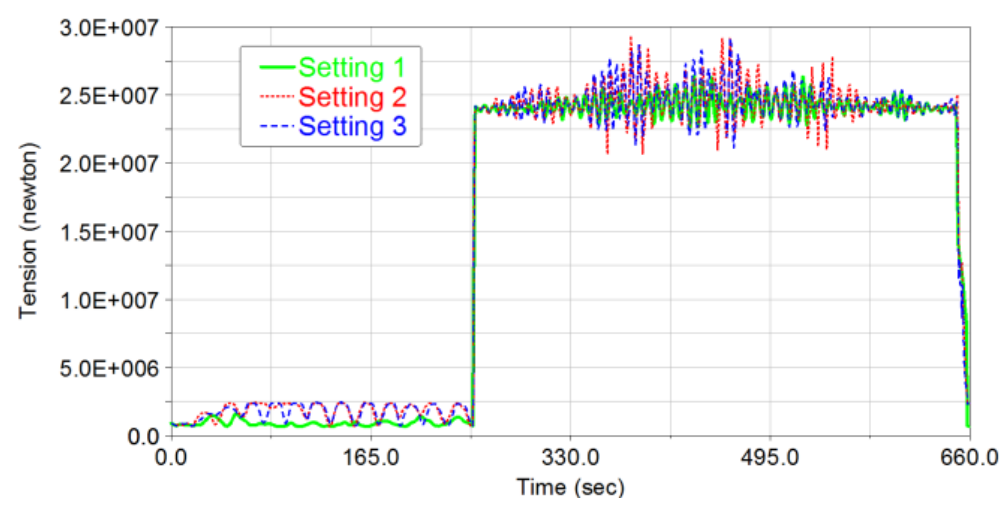

(c) Time response of the sling tension

Fig. 11 Dynamic response of hanging system

The swing angles of the hoisting system are $3.3^{\circ}$ and $2^{\circ}$ under environment setting 1 . The amplitude of angle Phi increases by 1.85 and 1.6 times in setting 2 and setting 3 respectively. The amplitude of angle Theta increases by 1.69 and 1.48 times in setting 2 and setting 3 respectively. The effect of the wave height is more considerable than the current velocity.

As shown in Fig. 11(c), the maximum amplitude of sling tension is $2.7 \times 10^{7} \mathrm{~N}$, about 1.125 times of the platform gravity in setting 1 .The maximum amplitudes of sling tension are $2.95 \times 107 \mathrm{~N}$ and $2.85 \times 107 \mathrm{~N}$ in setting 2 and setting 3 , which are 1.093 times and 1.056 times of the setting 1 respectively.

\subsection{Effects of the System Parameters on the Swing Angle and Sling Tension}

The parameters of the hoisting system include the pitch rate, rotational speed and sling length.

\subsubsection{Pitch Rate Effect}

The initial rotational angle is $0^{\circ}$ and the crane turntable rotates to $180^{\circ}$ before the platform being hoisted. There are ten seconds loading time before the platform is lifted up and then the hoisted object (platform) is lifted up by 5 meters. Then the absolute pitch rates are $0.002 \mathrm{rad} / \mathrm{s}$ and $0.004 \mathrm{rad} / \mathrm{s}$ respectively to understand the effects of the pitch rate on the swing angles and sling tension.

The time response of the swing angles and sling tension are shown in Fig. 12.

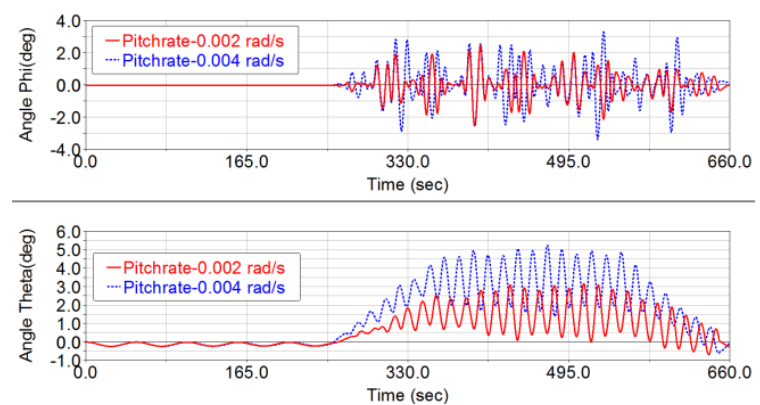

(a) Swing angle under different pitch rate

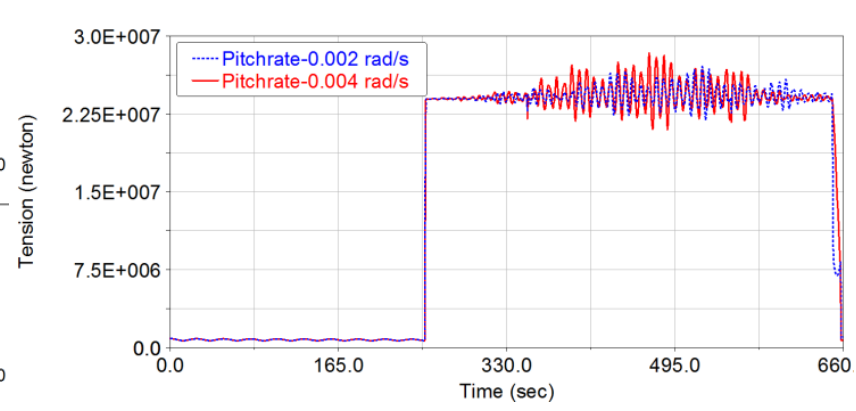

(b) Tension of sling under different pitch rate

Fig. 12 Dynamic response of hanging system 
As shown in Fig. 12(a), the maximum amplitude of the Phi angle increases from $2.5^{\circ}$ to $3.4^{\circ}$ and the angle Theta increases from $2.8^{\circ}$ to $5^{\circ}$ whenthe boom pitch rate changes from $0.002 \mathrm{rad} / \mathrm{s}$ to 0.004 $\mathrm{rad} / \mathrm{s}$. The influence of the pitch rate on angle Theta is more considerable than Phi. Actually in the hoisting operations, when the hoisted object is close to the hull, the crane operator should pay extra attention to avoid the hoisted object to run into the hull by adjusting the pitch rate.

The sling tension is produced by the weight of the hook only before the platform being hoisted, the main hook weights 90 tons. As shown in Fig. 12(b), the maximum amplitude of the sling tension increases from $2.625 \times 10^{7} \mathrm{~N}$ to $2.8 \times 10^{7} \mathrm{~N}$ when boom pitch rate is doubled.

\subsubsection{Rotation Speed Effect}

The pitch rate keeps zero after the hoisted object is lifted up and then the absolute rotational speed keeps $0.01 \mathrm{rad} / \mathrm{s}$ and $0.02 \mathrm{rad} / \mathrm{s}$ respectively to compare the swing angles and sling tensions to understand the effects of the rotational speed. The time response of the swing angle and the sling tension under the two crane rotational speeds are shown in Fig. 13.

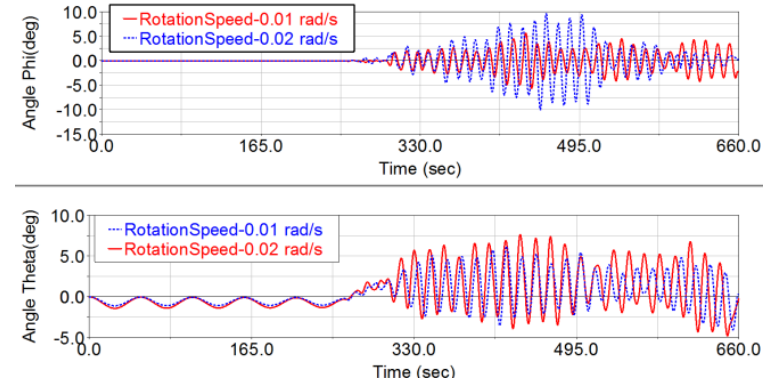

(a) Swing angle under the given rotation speeds

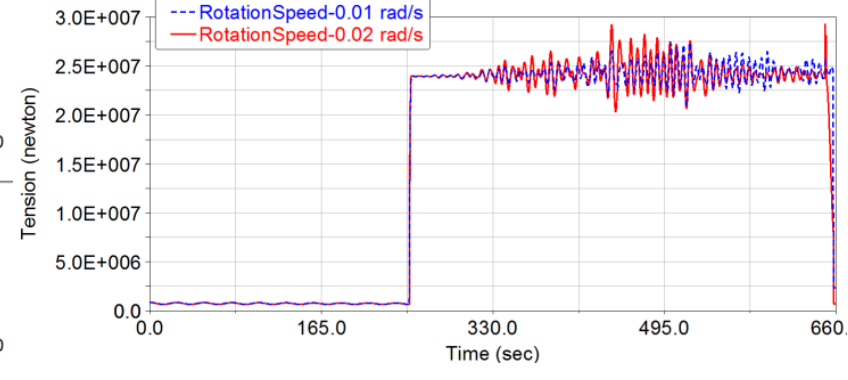

(b) Tension of sling under different rotation rate

Fig. 13 Time response of the swing angle and the sling tension

It can be seen in Fig. 13(a) that the amplitude of Theta increases from $6^{\circ}$ to $7.5^{\circ}$ and that of $P h i$ increases from $5.5^{\circ}$ to $10^{\circ}$ when the rotational speed increases from $0.01 \mathrm{rad} / \mathrm{s}$ to $0.02 \mathrm{rad} / \mathrm{s}$. The influence of the rotational speed on $P h i$ is more considerable than that on Theta.

Fig. 13(b) shows that the tension of the sling increases from $2.7 \times 107 \mathrm{~N}$ to $2.9 \times 107 \mathrm{~N}$ when the rotational speed of crane is doubled.

\subsubsection{Sling Length Effect}

In this simulation, the sling lengths are $60 \mathrm{~m}$ and $30 \mathrm{~m}$ respectively to compare the time responses of the swing angle and sling tension to understand the effects of the sling length. The distances from top of the platform to sea level are 50 meter and 85 meter respectively which are arranged in advance. The time responses of the swing angle and the tension with the sling lengths of $30 \mathrm{~m}$ and $60 \mathrm{~m}$ respectively are shown in Fig. 14.
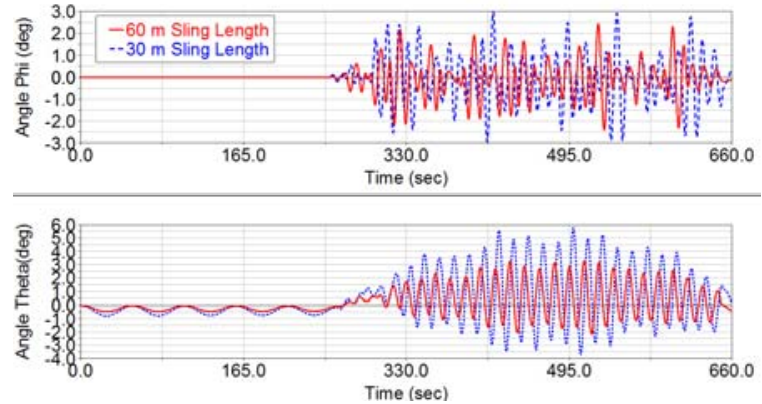

(a) Swing angle under different sling length

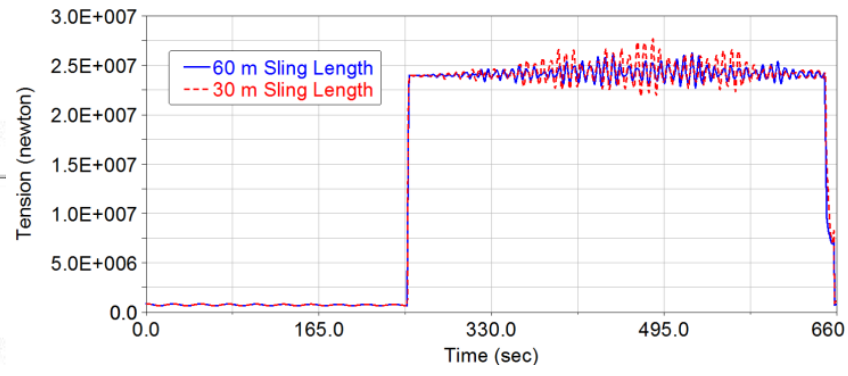

(b) Tension under different sling length

Fig. 14 The time responses of the swing angle and the tension

When the length of sling is reduced from $60 \mathrm{~m}$ to $30 \mathrm{~m}$, the amplitude of angle Theta increases from $3.2^{\circ}$ to $5.9^{\circ}$ around 1.84 times and $P h i$ angle amplitude increases from $2.4^{\circ}$ to $3.0^{\circ}$ only around 1.25 times, and the tension of the sling increases slightly from $2.6 \times 10^{7} \mathrm{~N}$ to $2.75 \times 10^{7} \mathrm{~N}$. 


\section{Sea-Trial and Verification}

To verify the accuracy of the simulation, the sea-trial of the hoisting system has been carried out on July 2015 in the south sea of China. The process data of the hoisting operation and installation of the platform have been recorded. The key parameters of the sea trail are listed in Table 2.

Table 2. Parameters of Sea Trial

\begin{tabular}{ccccc}
\hline Parameters & Platform mass & Wave height & Current velocity & Wave direction \\
\hline Value & 2372.94 tons & $2 \mathrm{~m}$ & $0.31 \mathrm{~m} / \mathrm{s}$ & $90^{\circ}$ \\
\hline
\end{tabular}

In the actual hoisting process, because the command and personnel scheduling process is rather slow, the lifting time tends to last a few days. The full data throughout the hoisting process are too hard to be recorded. The selected continuous data section of one hour after the platform had been hoisted are recorded and compared with the results of the hoisting simulation system. The sea trial data is shown in Fig 15.

(a)

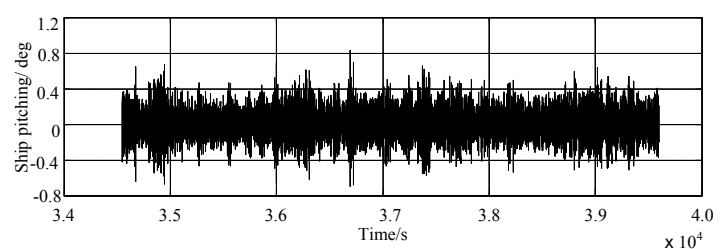

(b)

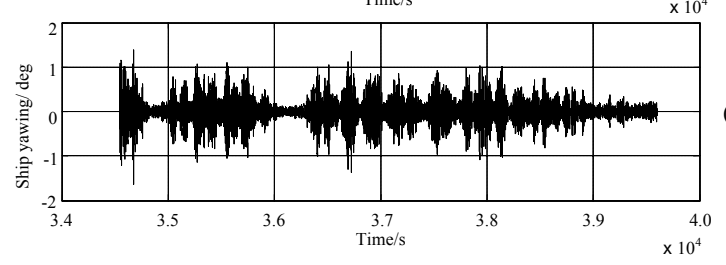

(c)
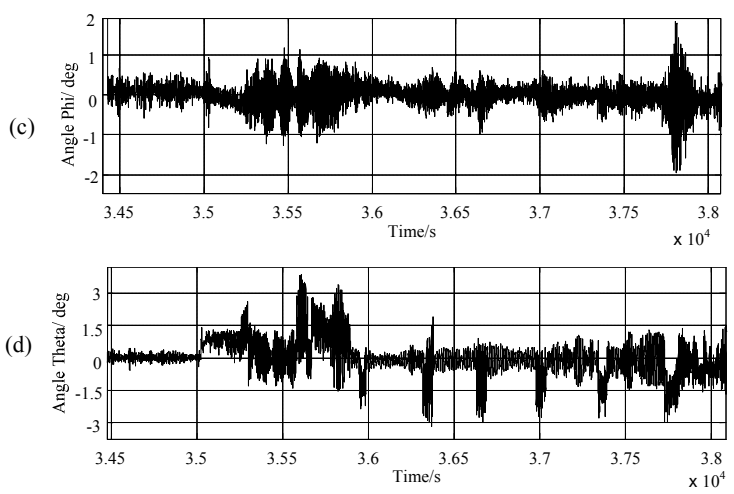

Fig 15. The data of the crane ship and the hoisting object. (a) Ship pitching time response, (b) Ship yawing time response, (c) Angle Phi Time response, (d) Angle Theta Time response

The sea trial data recorded in Fig 15 are compared with the results of the hoisting simulation of Fig 8 (b) and Fig 11 (a) and (b), as listed in the table 3.

Table 3. Results comparison of simulation system and sea trial

\begin{tabular}{ccccc}
\hline Parameter & Simulation / rad & Sea trial / rad & error & Relative error \\
\hline Ship pitching & $-0.8 \sim 0.7$ & $-0.7 \sim 0.84$ & 0.04 & $4.7 \%$ \\
Ship yawing & $-1.48 \sim 1.35$ & $-1.55 \sim 1.3$ & 0.07 & $4.5 \%$ \\
Angle Phi & $-2 \sim 2$ & $-1.9 \sim 1.9$ & 0.1 & $5.2 \%$ \\
Angle Theta & $-1.5 \sim 3.3$ & $-3.1 \sim 3.5$ & 0.2 & $5.7 \%$ \\
\hline
\end{tabular}

According to the comparison of ship pitching, yawing, angle Phi and Theta between the simulation and the sea trial, the relative error is less than $6 \%$. This error is acceptable for the hoisting visual simulation and the hoisting simulation system has been approved by the Offshore Oil Engineering Co., Ltd.

\section{Summary}

Adams, Simulink and analytics combined method can be used to predict the motion of the crane ship, the swinging of the hoisted object and the tension of the sling in various settings of the offshore environment. With this method the "Offshore Oil 201" is modeled and analyzed in various offshore environments. On the base of the simulations and analysis, the following conclusions can be drawn:

(1) The effect of the environmental interference is considerable, particularly the effect of the wave height. The wave height increasing from $2 \mathrm{~m}$ to $4 \mathrm{~m}$ will increases the ship heaving by 3.17 times, the ship yawing by 2.7 times, the pitching by 2.6 times and the rolling by 1.5 times. Meanwhile, the swing angles, Phi and Theta, are increased by 1.85 and 1.69 times respectively and the sling tension is increased by $9.3 \%$. The current velocity increasing from $0.31 \mathrm{~m} / \mathrm{s}$ to $0.62 \mathrm{~m} / \mathrm{s}$ will increase the ship heaving by 2.5 times, the ship swaying by 1.7 times, the ship yawing by 1.3 times, and the pitching by 
1.9 times and the swing angles, Phi and Theta, are increased by 1.6 times and 1.48 times respectively and the sling tension is increased by $5.6 \%$.

(2) The effects of the pitch rate and rotational speed are both considerable. The pitch rate increasing from $0.002 \mathrm{rad} / \mathrm{s}$ to $0.004 \mathrm{rad} / \mathrm{s}$ will increase the swing angles, Phi and Theta, by 1.36 times and 1.79 times and the sling tension by $6.7 \%$. The rotation speed increasing from $0.01 \mathrm{rad} / \mathrm{s}$ to $0.02 \mathrm{rad} / \mathrm{s}$ will increase the swing angles, Phi and Theta, by 1.25 times and 1.82 times, and the sling tension by $7.4 \%$. The Pitch rate effects on the angle Theta, which is in the XOZ plane, more than the angle $P h i$, which is in YOZ plane; on the contrary, the rotation speed effects on the angle Phi more than the angle Thera.

(3)The length of the sling is another point to be considered in advance. Reducing the sling length from $60 \mathrm{~m}$ to $30 \mathrm{~m}$ will increase the swing angles, Phi and Theta, by 1.25 times and 1.84 times respectively and the sling tension by $6.7 \%$.

The simulation of hoisting parameters is of great significance to study the movement law of offshore hoisting operations. The simulation also provides the basis for the development of actual hoisting construction plan to improve the safety of the hoisting operation.

\section{References}

[1]. Yu H, Lian Z, Lin T, et al. Experimental and numerical study on casing wear in highly deviated drilling for oil and gas. Advances in Mechanical Engineering. Vol. 8(2016) No. 7, p. 1-15.

[2]. Liu J, Xiao Q. The Influence of Operation Pressure on the Long-Term Stability of Salt-Cavern Gas Storage. Advances in Mechanical Engineering. Vol. 7(2014) No. 5, p. 558-564.

[3]. Sun C, Yu B. Analyses on Heating Energy Saving of Two Hot Waxy-Crude Oil Pipelines Laid Parallel in One Ditch. Advances in Mechanical Engineering. Vol. 5(2013) No. 2, p. 167-182.

[4]. Stanivuk T, Zore I, Simić M. Importance of port, floating and ship cranes in maritime transportation. Maritime, transport and logistics science: conference proceedings 17th International Conference on Transport Science. Portorož, Slovenia, 2015.5, p. 434-448

[5]. Wang S. The Effect Analysis of Ocean Wind \& Wave Load on 7500 t Floating Crane ConFiguration. China Heavy Equipment. Vol. 106(2009) No. 3, p. 568-679.

[6]. Zhu F, Jiang Y, Li W. Analysis and Calculation of Ocean Current Load and Wave Load on a Floating Crane under a Normal Working State. Journal of Coastal Research. Vol. 73(2015) No. 3, p. 48-53.

[7]. Nesin D Y, Dushko V R. Numerical Model of the Large Carrying Capacity Crane Ship with the Fully Revolving Topside. Procedia Engineering. Vol. 25(2015) No. 1, p. 1082-1091.

[8]. Li Y, Wang S, Li B. Improved Visual Hook Capturing and Tracking for Precision Hoisting of Tower Crane. Advances in Mechanical Engineering. Vol. 5(2013) No. 2, p. 260-280.

[9]. Chen J F. Load Test Research on Great Crane of 28000t Great Crane Ship. Ship Standardization Engineer. Vol. 48(2015) No. 2, p. 37-39.

[10]. Wang P. Dynamics Analysis and Modeling of Ship-mounted Boom Crane. Journal of Mechanical Engineering. Vol. 47(2011) No. 20, p. 34-40.

[11]. Neupert J, Heinze T, Sawodny O, et al. Observer design for boom cranes with double-pendulum effect. Proceedings of the IEEE International Conference on Control Applications. Saint Petersburg, Russia, 2009.9, p. 1545-1550.

[12]. Qian D, Tong S, Lee S G. Fuzzy-Logic-based control of payloads subjected to double-pendulum motion in overhead cranes. Automation in Construction. Vol. 65(2016) No. 5, p. 133-143. 
[13]. Solazzi L, Incerti G, Petrogalli C. Estimation Of The Dynamic Effect In The Hoisting Operations Of A Boom Crane. Conference on Modelling and Simulation. Brescia, Italy, 2014, p. 309-315.

[14]. Chowdhury D, Basu B. Spin transport in non-inertial frame. Physica B Condensed Matter. Vol. 448(2014) No. 9, p. 155-161.

[15]. Bertram V. Practical Ship Hydrodynamics. Butterworth-Heinemann, 2012, p. 265-268.

[16]. Eugenio O, Julio G, Idelsohn S R, et al. Ship Hydrodynamics. Encyclopedia of Computational Mechanics. John Wiley \& Sons, Ltd, 2004, p. 181-185.

[17]. Lv X, Wu X, Sun J, et al. Trim Optimization of Ship by a Potential-Based Panel Method[J]. Advances in Mechanical Engineering. Vol. 5(2013) No. 7, p. 33-51.

[18]. Koo W C, Kim M H. Numerical simulation of nonlinear wave and force generated by a wedge-shape wave maker. Ocean Engineering. Vol. 33(2006) No. 8, p. 983-1006.

[19]. Kashiwagi M. Wave drift force in a two-layer fluid of finite depth. Journal of Engineering Mathematics. Vol. 58(2007) No. 1, p. 51-66.

[20]. Gkikas G D. A Nonlinear Response Amplitude Operator for Complex Maritime Dynamical Systems, Wave Energy Converters and Offshore Applications. International Ocean and Polar Engineering Conference. Hawaii, USA, 2015, p. 1-8.

[21]. Ishihara T, Fujino Y. Development of a new wake model based on a wind tunnel experiment. Global Wind Power. Vol. 105(2004) No. 1, p. 33-45.

[22]. Xiao H, Huang W, Tao J, et al. Numerical modeling of wave-current forces acting on horizontal cylinder of marine structures by VOF method. Ocean Engineering. Vol. 67(2013) No. 3 , p. 58-67. 